\title{
La crisis del marxismo en una perspectiva latinoamericana Diálogos entre el morenismo y los estudios subalternos
}

\author{
The Marxism's crisis in a Latin American perspective \\ Dialogs between the morenism and the subordinate studies
}

Julia Exposito *

\begin{abstract}
Resumen
¿Qué impactos suponen el cómo se teoriza la “crisis del marxismo” sobre lo políticocultural, la/las subjetividades y la "estructura" social? Creemos que los aportes que se han realizado en este sentido se encuentran vinculados con aquello que podríamos denominar "pensamiento europeo". En este sentido, y con el objetivo de aportar al debate actual en torno a la "crisis del marxismo", creemos que es necesario realizar un recorrido por las producciones de ciertos autores latinoamericanos que, de algún modo, han hecho eco de esta problemática. Consideramos que la dupla Nahuel Moreno- John Beverley puede ser interesante para relevar estos debates, puesto que nos permite abordar esta temática desde distintas perspectivas, las cuales encierran en sí mismas, distintas definiciones del marxismo.
\end{abstract}

Palabras claves: sujeto-marxismo-subalterno-crisis.

\begin{abstract}
What are the impacts as theorizes the "crisis of marxism" on the politicalcultural,/subjectivities and the "structure" social? We believe that the contributions that have been made in this direction are linked with what could be termed "European thought". In this sense, and with the aim of contributing to the ongoing debate about the "crisis of Marxism", we believe that there is a need for a tour of the production of certain Latin American authors that, somehow, have echoed this problematic. We believe that the duo Nahuel Moreno-John Beverley can be interesting for relieving these debates, because it allowed us to address this issue from different perspectives, which contain in themselves, different definitions of marxism.
\end{abstract}

Keywords: subject-marxism-subaltern -crisis

\footnotetext{
* Argentina, Magister en Estudios Culturales por la Universidad Nacional de Rosario, Licenciada en Ciencia Política por la Universidad Nacional de Rosario y Doctoranda del Doctorado en Ciencias Sociales por la Universidad Nacional de Buenos Aires. Integrante del Centro de Estudios de Teoría Crítica, Becaria doctoral del CONICET; expositojulia@gmail.com.
} 


\section{Introducción}

Hablar en la actualidad del marxismo y su "crisis" se ha convertido, indudablemente, en una de las empresas más difíciles. ¿Existe hoy una crisis del marxismo?, y si asentimos ¿De qué tipo de crisis se trata? En primer lugar, la dificultad radica en la constatación de un amplio arco de definiciones desde las que se puede dar respuesta a estas preguntas. En segundo lugar, porque estas cuestiones nos conducirán a otra, quizás más compleja: la de preguntarnos por la naturaleza misma del pensamiento marxista. Se hace válida, de esta manera, la cuestión planteada por C. Castoriadis: “¿De qué marxismo, en efecto habrá que hablar?"?.

Consideramos, que por la amplia producción y por los extensos márgenes de controversias que sobrelleva, la "crisis del marxismo" es un tema crucial para un pensamiento políticocultural crítico $^{3}$. Habitamos un mundo, y hasta podríamos aventurar, una cultura, que conserva la marca de la herencia marxista. Como afirmara Derrida:

Será siempre un fallo no leer y releer a Marx. Es decir, también a algunos otros [marxistas] (...). Será cada vez más un fallo, una falta contra la responsabilidad teórica, filosófica, política. Desde el momento en que la máquina de dogmas y los aparatos ideológicos 'marxistas' (...) están en trance de desaparición, ya no tenemos excusa solamente coartadas, para descentrarnos de esta responsabilidad. (...) No hay porvenir sin Marx. Sin la memoria y sin la herencia de Marx. ${ }^{4}$

Este nuevo siglo, y esta nueva época, denominada "posmoderna”, tienen como hito político una caída, la del muro de Berlín, que terminó de arrastrar junto con él gran parte del bagaje de saberes y certezas del discurso marxista. De este modo, E. Palti sostendrá que "la disolución de la URSS, (...), para muchos de los enrolados en las filas de la izquierda revolucionaria representó una experiencia traumática (...); abrió, para ellos una suerte de quiebra de inteligibilidad en la que todas sus anteriores certidumbres colapsaron ${ }^{5}$. En este sentido, N. Moreno, desde una perspectiva militante declarará "los marxistas revolucionarios, en general sostenían que el capitalismo se dirigiría a la catástrofe (...). Todos nosotros hemos compartido esa concepción, (...) decíamos que (...), se hundiría el capitalismo para dar lugar a una sociedad socialista".. El "sentido marxista de la historia"

\footnotetext{
2 Cornelious Castoriadis, La institución imaginaria de la sociedad. Marxismo y teoría revolucionaria (Barcelona: Tusquets, 1993) 17.

${ }^{3}$ Entendemos al vínculo entre lo político y lo cultural como lo hacen Szurmuk y McKee Irwin en su "Diccionario de Estudios culturales latinoamericanos", donde afirman que la cultura es plausible de asumir una función política especifica “tanto en la construcción de hegemonías como en su desestabilización” (2009:71), en tanto se entienda a la cultura como un espacio de "intervención y agonía, pero igualmente como zona de resistencia en los procesos coloniales/neo/poscoloniales, como ese esfuerzo para descolonizar y para su nueva articulación en procesos constitutivos de las identidades”; Ver Mónica Szurmuk y Robert McKee Irwin, Diccionario de Estudios Culturales Latinoamericanos (México: Siglo XXI Editores, 2009$) 70$.

${ }^{4}$ Jacques Derrida, Espectros de Marx. El estado de la deuda, el trabajo del duelo y la nueva internacional (Madrid: Trotta, 1995) 27.

${ }^{5}$ Elias Palti, Verdades y saberes del marxismo. Reacciones de una tradición política ante su “crisis” (Buenos Aires:Fondo de cultura económica, 2005) 19.

${ }^{6}$ Nahuel Moreno, Conversaciones con Nahuel Moreno (Buenos Aires: Antídoto, 1986) 1.
} 
parecía, ahora, descentrarse, dando lugar a la especulación de la no posibilidad del socialismo, algo impensable para cualquier marxista. Así se nos revela el carácter peculiar de esta crisis: "La pérdida del Sentido deja en pie aún la pregunta por el sentido, o más exactamente, por los múltiples sentidos, pues el sentido con minúscula oculta mal cuánto se ha cedido de la búsqueda política del Sentido" 7.

La pregunta que se nos presenta, entonces, es qué implicancias teóricas, metodológicas y políticas suponen el cómo se piensa la llamada “crisis del marxismo”. Es decir, ¿las distintas resoluciones teóricas sobre la crisis del marxismo, no conllevarían impactos disímiles en el modo de pensar: las formas organizativas y/o institucionales, es decir los modos políticos-culturales; las subjetividades con potencialidades emancipatorias; y la forma más general de organización de la "sociedad”, aquello que el marxismo denominaba "estructura”?

En función de lo hasta aquí expuesto, nos parece pertinente volver sobre nuestra pregunta: ¿qué impactos suponen el cómo se teoriza la “crisis del marxismo" sobre lo políticocultural, la/las subjetividades y la "estructura” social? Creemos que los aportes que se han realizado en este sentido se encuentran vinculados con aquello que podríamos denominar "pensamiento europeo". Aportes que si bien generan una suerte de panorama y una contribución fundamental en la cuestión, no agotan sus posibilidades. En efecto, sería un fallo pretender cerrar esta problemática desde una visión eurocéntrica, dada la cantidad de debates y teorizaciones en torno al marxismo que se han realizado en los demás continentes. En este sentido, y con el objetivo de aportar al debate actual en torno a la "crisis del marxismo", creemos que es necesario realizar un recorrido por las producciones de ciertos autores latinoamericanos que, de algún modo, han hecho eco de esta problemática. Un análisis de este tipo podría generar un aporte interesante a un pensamiento político-cultural contemporáneo que pretenda ser crítico.

De este modo, hemos escogido dos corrientes, ilustradas por sus dos máximos exponentes (si bien comprendemos que los escritos de los autores, de algún modo, operan como pensamiento colectivo), para relevar la problemática de las crisis del marxismo en Latinoamérica: el Movimiento al socialismo (MAS), ejemplificado por ciertos escritos relevantes de Nahuel Moreno, y los Estudios subalternos latinoamericanos, expuestos por textos de uno de sus fundadores John Beverley. Consideramos que la dupla MorenoBeverley puede ser interesante para relevar estos debates, puesto que nos permite abordar esta temática desde distintas perspectivas (perspectivas las cuales encierran en sí mismas, distintas definiciones del marxismo $)^{8}$. No obstante el recorrido por distintas tradiciones, ambos grupos son herederos de ciertos debates teóricos comunes, al mismo tiempo que se encuentran inmersos en las vicisitudes de una misma coyuntura tanto internacional como latinoamericana (ambas teorizaciones discuten el contexto de finales de los '80). El desafío metodológico será, entonces, el de analizar las producciones teóricas de estos autores como

\footnotetext{
${ }^{7}$ Omar Acha, "La irresistible seducción filosófica del marxismo", Revista herramienta No33, Argentina, (2006: 2).

${ }^{8}$ Esta dupla nos permitiría, no solamente enmarcar el debate dentro de herencias marxistas disímiles, aunque no opuestas, sino que también nos habilitaría, en cierta manera, a oscilar en la tensión, siempre existente en el marxismo, entre teoría y práctica. Mientras que Moreno, proveniente de la tradición trostkista, fue un dirigente abocado a la acción política partidaria; Beverley, es ante todo un intelectual militante del ámbito universitario, ligado a una tradición de los Estudios culturales latinoamericanos.
} 
“espacios discursivos”, ligadas a su contexto de aparición. En este sentido, “toda acción social tiene un sentido, ella se constituye bajo la forma de secuencias discursivas". 9 y por ello el discurso es co-extensivo de lo social. Por lo tanto, la categoría de "discurso", lejos de inferir una tendencia “idealista”, supone pensar la bibliografía como un complejo entramado de teoría y práctica, donde la totalidad estructurada de estos espacios es siempre contingente. Dicha contingencia, supone por tanto una articulación que puede ser explorada, siguiendo las conexiones conceptuales (que revelan su carácter de no "necesarias”) y de esta manera sacar provecho de un entrecruzamiento entre las producciones de los autores y los temas, revelando los puntos nodales para nuestra investigación.

Para exponer los objetivos planteados, nos proponemos en este artículo realizar, en un primer apartado una suerte de mapeo sobre determinadas posturas frente a la actual crisis del marxismo, puesto que consideramos que aporta a la discusión sobre los autores trabajados. En un segundo momento, pretendemos indagar sobre el contexto más general en el cual los autores realizan la mayor parte de su obra significativa para este trabajo. A la vez que este análisis es aclaratorio en relación al contexto que hacen referencia los autores cuando teorizan sobre la crisis del marxismo. Para ir luego, en un tercer apartado a referirnos al contexto teórico-conceptual que permitirá luego realizar un cuarto apartado que trabaja ya específicamente sobre las obras de los autores -recortada según el contexto trabajado- para distinguir que reformulaciones teóricas presentan frente el discurso marxista clásico a la hora de pensar la crisis de este pensamiento.

\section{Un mapeo sobre la actual crisis del marxismo}

El debate sobre la crisis del marxismo, como marcábamos más arriba, implica sin dudas una tarea ardua y compleja. En este sentido, es que hemos decidido, a los fines prácticos de este trabajo, comenzar exponiendo una suerte de delimitación teórico-conceptual, que si bien entendemos no agota la problemática, es útil para generar un contexto más amplio sobre posturas frente a la crisis, a la vez que es atinado para referenciar los puntos clave que prendemos tratar en la obra de Moreno y Beverley. Es así que podemos decir que las respuestas al por qué de la crisis del marxismo rondarán en torno a su "saber" y su "verdad”. Es decir, la crisis parecería desdoblarse. Por un lado, supone una suerte de puesta en cuestión de los pilares teóricos del marxismo (el marxismo en tanto "saber") y, por el otro, sería resultado del balance negativo, incluso de la derrota, de la práctica política marxista en el siglo XX (la puesta en cuestión de la "verdad” marxista de la historia).

El desdoblamiento entre saber y verdad, complejiza los debates en torno a qué significa la crisis del marxismo. L. Althusser distinguirá que hacia dentro del marxismo hay tres formas generales de reaccionar frente a esta crisis. La primera, afirma, se caracterizará por “(...) cerrar los ojos para no ver, y callar: oficialmente el marxismo no conoce crisis alguna, son

\footnotetext{
${ }^{9}$ Rosa Nilda Buenfil Burgos, “Foucault y la analítica del discurso”, ponencia para Coloquio Aniversario del Nacimiento de Michel Foucault, México, (1996).
} 
los enemigos quienes la han inventado" ${ }^{10}$. Dentro de este punto podemos ubicar a las visiones más ortodoxas, o incluso a los análisis de algunos partidos tradicionales dentro del discurso marxista tal como se había consolidado tras las primeras décadas del Siglo XX. También podemos situar aquí a algunos teóricos, como por ejemplo a P. Anderson, quien sostendrá que la actual crisis el marxismo no es tal, sino que por el contrario sería más preciso hablar de un colapso del movimiento comunista y de la III Internacional: "me parece francamente aberrante —es invertir la realidad—, describir la fase actual como un período de 'crisis del marxismo', en lo que se refiere a la instancia teórica de la producción del marxismo como fuente de pensamiento" ${ }^{11}$. Las contradicciones en el plano de la práctica no suponen un cuestionamiento del discurso marxista.

La segunda forma mencionada por Althusser, consiste en comprender que existe una crisis, "y sufrirla mientras se continúan buscando motivos reales de esperanza en las fuerzas del movimiento obrero y popular” ${ }^{12}$. Alegando que se trata de una crisis cíclica más, aunque quizás más intensa que las anteriores, la crisis (más allá de su intensidad) supone su eventual solución por medio de alguna revisión interna dentro de la tradición marxista. En este sentido localizamos teorizaciones como la de M. Löwy, que señala el peligro de ubicarnos "en el terreno de la 'crisis del marxismo' [puesto que] vuelven a florecer el liberalismo burgués, el positivismo, la metafísica idealista o materialismo vulgar, el biologismo social, el oscurantismo reaccionario” ${ }^{13}$. Para Löwy, el marxismo sigue siendo el horizonte intelectual de nuestra época, por lo tanto el punto fundamental para salir de esta situación crítica precisa de una renovación dentro de la teoría marxista: "Esta renovación implica 'necesariamente' el enriquecimiento del marxismo con el aporte de los nuevos movimientos sociales, (...), exige también su 'fertilización' por las formas más avanzadas y productivas del pensamiento teórico no marxista (...). Finalmente, el desarrollo creador del marxismo y la superación de su actual 'crisis' requieren, paralelamente a la radicalización de su negatividad dialéctica, el restablecimiento de su dimensión utópica” ${ }^{14}$.

El tercer tipo de reacción descripta por Althusser frente a la crisis "es tomar una perspectiva histórica, teórica y política suficiente para tratar de descubrir, (...), el carácter, el sentido y el alcance de esta crisis. Si se acierta, es posible también cambiar de lenguaje. En vez de comprobar: 'El marxismo está en crisis', decir: ‘¡Por fin ha estallado la crisis del marxismo!’” ${ }^{15}$. Es precisamente en este punto donde se ubicará el propio Althusser, entendiendo por crisis del marxismo "un fenómeno contradictorio que debe pensarse a escala histórica y mundial, y que (...) rebasa los límites de la 'teoría marxista'; (...) concierne al conjunto de las fuerzas que toman al marxismo como punto de referencia, a sus organizaciones, sus objetivos, su teoría, su ideología, sus luchas” ${ }^{16}$. De este modo, para Althusser, desde el cisma chino-soviético aparecen grandes conflictos en el interior mismo

\footnotetext{
${ }^{10}$ Louis Althousser, “Dos o tres palabras (brutales) sobre Marx y Lenin”, Eco. Revista de la cultura de occidente No 197, Bogotá (1978:515).

${ }^{11}$ Perry Anderson, “¿Existe una crisis del marxismo?”, Revista Dialéctica №9, 145-158, México (1980:148).

${ }^{12}$ Louis Althusser, "Dos o tres palabras..." 515.

${ }^{13}$ Michael Löwy, "Marx un siglo después”, El Rodaballo, Revista de cultura y política No 1, (1994:4).

${ }^{14}$ Michael Löwy, "Marx un siglo..." 6-7.

${ }^{15}$ Louis Althusser, "Dos o tres palabras..." 515.

${ }^{16}$ Louis Althusser, "Dos o tres palabras..." 513.
} 
de la tradición y militancia marxista, que ponen en cuestión la interpretación de la historia del marxismo. Por lo tanto, para Althusser habría, no sólo una crisis política, sino también, y más importante aún, una crisis teórica del marxismo:

Es en [un] sentido, profundamente político, que me parece inevitable hablar hoy de crisis del marxismo. El resquebrajamiento de las certezas heredadas de una larga tradición, la de la II y luego de la III Internacional, los efectos ideológicos y teóricos de la crisis manifiesta (escisión entre China y la URSS) y encubierta (entre los partidos comunistas occidentales y la URSS), el abandono solemne o silencioso de principios (como la 'Dictadura del proletariado’) sin una razón teórica confesable, la diversidad de las preguntas y las respuestas, la confusión de los lenguajes y de las referencias, traicionar; y enuncian la existencia de dificultades críticas de la propia teoría marxista, de una crisis teórica del marxismo ${ }^{17}$.

Es interesante, a las tres formas althusserianas de reaccionar ante de la crisis, agregarle una más. Nos referimos a concebir esta crisis del marxismo como el símbolo de su "muerte”, como una crisis general, que obligue a la demolición y abandono de dicho discurso. En esta línea, para Castoriadis, por ejemplo, “el marxismo he llegado a ser una ideología en el mismo sentido que Marx daba a ese término: un conjunto de ideas que se relacionan con una realidad, no para esclarecerla y transformarla, sino para velarla y justificarla en lo imaginario" 18 . Este autor afirmará que los dos pilares de la teoría marxista, el desarrollo de las fuerzas productivas y la lucha de clases, son contradictorios tanto en sí mismos como en su vinculación en tanto motores de la historia, y que a su vez son dos universos disímiles que generan formas distintas de pensar la filosofía, la política, la revolución. Para Castoriadis entonces, "la concepción materialista de la historia nos aparece hoy en día insostenible, (...) no podemos mantener más la filosofía marxista de la historia” ${ }^{19}$.

Para Palti las cuatro formas descriptas de reaccionar ante la crisis no agotan la problemática señalada. Si bien, en su análisis, la actual crisis de la tradición marxista no podría enmarcarse como una crisis cíclica, tampoco debería hablarse de una crisis general que declare la "muerte del marxismo":

Toda verdadera 'crisis conceptual', como la que intentamos explorar (...), comienza por la puesta en crisis del propio concepto de 'crisis'. Ésta visión de la crisis surge, precisamente, de la desarticulación de su marco implícito de nacimiento-destrucción-muerte-regeneración; disloca el dispositivo categorial médico-jurídico en que hunde sus raíces conceptuales; destruye el sentido del tiempo (kairós), sin que por ello nos devuelva al puro acontecer (chronos), sino que abre a la pregunta por lo que viene después del sentido, por el sentido luego del fin del Sentido ${ }^{20}$.

\footnotetext{
${ }^{17}$ Louis Althusser, “Dos o tres palabras...” 515.

${ }^{18}$ Cornelious Castoriadis, La institución imaginaria... 20.

${ }^{19}$ Cornelious Castoriadis, La institución imaginaria... 64.

${ }^{20}$ Elias Palti, Verdades y saberes del marxismo... 17-18.
} 
Para Palti, entonces, “la crisis contemporánea sería definitiva y al mismo tiempo insuperable. En efecto, lo que los denodados pero insatisfactorios esfuerzos de salvar al marxismo como saber o como práctica política delatan, es la imposibilidad de ir más allá del marxismo, una vez que éste ha fracasado" 21.

Ahora bien, entendemos que es necesario por la antes dicho enfatizar dónde nos ubicaremos nosotros en este gran debate sobre la actual crisis del marxismo. Sostenemos que, se hace indispensable pensar la crisis del marxismo tanto en un plano teórico como practicopolítico. De este modo, y como decíamos al comienzo, la “crisis” podría ser desdoblada, con fines analíticos, entre una suerte de debate teórico del marxismo (su saber), y una suerte de puesta en cuestión y de reformulación de su práctica política (su verdad). Puesto que consideramos, junto a Sazbón (2002), que el propio marxismo desde sus orígenes ha demostrado ser una teoría de la praxis, que por ende no se encuentra escindida de las coyunturas político-económicas particulares, creemos que no es posible desvincularlo de la época en la que ha surgido: aquella signada por el desarrollo del sistema capitalista como tal. En efecto, si algo nos ha mostrado la propia historia del marxismo es que ella se encuentra intímamente ligada a las "crisis" tanto del sistema capitalista en general, como a los vaivenes de las luchas emancipatorias, en particular. Teoría y práctica son, por lo tanto, dos ejes inseparables para pensar la historia del marxismo. Veamos ahora entonces esta vinculación en la obra de Moreno y de Beverley.

\section{De luchas y derrotas. En busca de un contexto histórico de las últimas décadas del siglo XX.}

Las experiencias políticas de la izquierda a nivel internacional hacia fines de los '80 y principios de los '90, estuvieron fuertemente condicionadas por el fin de la experiencia de los socialismos reales, fin que se produjo como resultado de una concurrencia de hechos en el panorama global y los procesos sociales internos de los países que pertenecían a la zona de influencia de la URSS durante el desarrollo de la Guerra Fría, y que en 1989 tuvo como hito de alto impacto simbólico la caída del Muro que dividía a Berlín desde 1961. Si a esto le añadimos las transformaciones en la estructura económica y política que venían siendo llevadas adelante por el gobierno del Partido Comunista Chino (marcadas a fuego por las jornadas represivas de Tian’anmen en 1989); la crisis de la revolución cubana con el endurecimiento del régimen castrista; la derrota electoral del FSNL en Nicaragua, sólo por mencionar algunas, comprenderemos que todas estas mutaciones contribuyeron a que el clima de derrota de esos años se extendiera cada vez más. Cabe agregar que estas transformaciones a menudo generaron, incluso desde dentro de la misma izquierda (y podríamos decir, sobre todo desde ella), una crítica hacia los procesos revolucionarios que sostenía que éstos en amplias ocasiones habían "traicionado" las premisas emancipatorias: enquistándose en el poder; persiguiendo políticamente a disidentes (siendo el encarcelamiento la "menor" de las consecuencias); empobreciendo a los trabajadores, campesinos, etc.

\footnotetext{
${ }^{21}$ Omar Acha, "La irresistible...” 1.
} 
De este modo, por ejemplo, la derrota electoral del FSNL, es analizada en clave de las trasformaciones político-económicas restrictivas que impulsa el mismo FSNL a partir del '88: “A partir de mediados de 1988 el gobierno sandinista encaró una política económica que favoreció a los ricos y perjudicó a los pobres, y que además los agredió ideológicamente y ratificó en el discurso oficial la ausencia de un especio legítimo para buena parte de las bases sociales del sandinismo" 22 . Al mismo tiempo que, "la organización partidaria fue coincidiendo y solapándose con la estructura administrativa del Estado" 23 .

Junto con este proceso de "derrota" de los socialismos reales, se desarrollaban fuertes mutaciones dentro de la lógica de producción capitalista. El contexto económico global se encontraba signado por el quiebre del tándem fordista/taylorista, momento en el cual la organización vertical del fordismo era subvertida por la aparición del toyotismo, que suponía una organización radicalmente nueva: la tendencia hacia una horizontalización de la forma del trabajo, que se hallaba en una mejor sintonía con la nueva "lógica neoliberal" que promovía el debilitamiento del modelo del Estado de Bienestar ${ }^{24}$.

En términos ideológicos es importante afirmar que, el auge de la "lógica neoliberal” alentó la instalación de dispositivos discursivos que demonizaron la política como práctica y como herramienta de disputa por el orden social, vaciándola de sus contenidos conflictivos y recortando su campo de intervención en función de la multiplicación de los abordajes técnicos -como desvinculados de lo político- y la consolidación de una tecnocracia lista para llevar adelante el desmantelamiento de redes sociales y políticas más o menos institucionalizadas (sindicatos, gremios, partidos políticos, organizaciones de base, etc.).

Es en este complejo contexto internacional en el cual los grupos y autores escogidos comienzan a poner en jaque no sólo los aportes tradicionales del marxismo, sino, incluso, sus anteriores producciones teóricas. Si las teorizaciones de Moreno y de Beverley parten de un diagnóstico común de derrota, sin embargo se diferencian en sus exploraciones críticas acerca de las lógicas políticas llevadas a cabo por la izquierda.

Creemos que para ambos autores el problema radicaba en un debate en torno a las subjetividades que construían-constituían los procesos revolucionarios. Sin embargo, el problema era entendido por caminos disímiles. Para Moreno ese problema era leído en clave de “contenido clasista”, es decir, bajo el apoyo de qué clases sociales se sostenían los procesos revolucionarios:

Tomemos ejemplos cercanos: Cuba y Nicaragua. En los dos se produjo un fenómeno similar. Fidel Castro puso de presidente de la República a Urrutia, un importante agente político de la burguesía y el imperialismo. Lo mismo hizo el FSLN nicaragüense con Violeta Chamorro y Róbelo, (...) representantes de la burguesía (...). Lógicamente, si el actual gobierno

\footnotetext{
22 Carlos Vilas, “Nicaragua: El camino de la derrota electoral y el porvenir de la revolución sandinista”, Reviste Realidad N 14, Marzo-Abril, (1990):143.

23 Salvador Martí, "Nicaragua postrevolucionaria: el laberinto sandinista y la difícil consolidación democrática”, Afers Internacionals, núm. 34-35, (1996): 150.

${ }^{24}$ Ricardo Antunes, ¿Adiós al trabajo? Ensayo sobre las metamorfosis y el rol central del mundo del trabajo. (Buenos Aires: Ediciones Herramienta, 2003) 36.
} 
nicaragüense es frente populista no puede ser obrero y campesino ni haber expropiado a la burguesía ${ }^{25}$.

Por su parte, Beverley y los estudios subalternos argumentaban que el problema era que los procesos revolucionarios dejaban por fuera de su "sujeto" a sectores que eran subalternos, recreando las relaciones dominantes/subalternos en una nueva forma. Las dificultades de la revolución cubana o de la nicaragüense radicaban en que habían comenzado a "rearticular la relación dominante/subalterno, no habían radicalizado suficientemente esa relación. Una "estructura" -en el sentido que dan a esa palabra los estructuralistas- continuaba produciendo efectos políticos "extraños", contraproductivos" ${ }^{26}$. Este fenómeno se expresaba en que tanto negros, como indios, chicanos y mujeres, al mismo tiempo que ciertos modelos alternativos de sexualidad y de corporalidad, no habían entrado en pacto con el estado revolucionario. De este modo, si para Moreno el problema radicaba en el "contenido clasista" de los procesos revolucionarios, para el grupo de estudios subalternos, el problema se presentaba en que el "cierre" sectario del sujeto revolucionario, velaba la posibilidad de concebir al sujeto emancipatorio en su heterogeneidad constitutiva.

\section{Un debate (de época) con y contra el marxismo}

En términos generales, los debate teóricos fundamentales, de finales de la década del ' 80 principios del '90, se centraban en la pregunta por la posibilidad óntico-ontológica misma del "sujeto" emancipatorio predicado por la tradición marxista. El eje central de problema comenzaba por remarcar que el marxismo, en tanto perteneciente al pensamiento propiamente moderno, había teorizado sobre un sujeto, que si bien suponía toda una serie de complejidades y trasformaciones para el pensamiento, se encontraba bajo la lógica reinante del supuesto cartesiano de la subjetividad: el sujeto como cogito, el sujeto del ego, el sujeto unívoco.

En este sentido, uno de los puntos claves de los teóricos, militantes, etc., fue el de discutir esta idea de subjetividad. Esto tuvo como resultado diversas connotaciones en torno a la relación antes trabajada entre "saber" y "verdad" del marxismo. El debate giraba en torno a la posibilidad de mantener el discurso marxista, sabiendo que era necesario transformar sus conceptos fundamentales, es decir, se presentaba la incógnita de si determinadas herramientas teóricas que el marxismo proporcionaba en términos de saber aun continuaban vigentes (como por ejemplo: "lucha de clase", "modo de producción", "estructura/superestructura", "alienación”, etc). Por otra parte, esa discusión de índole teórica se relacionaba inevitablemente con la pregunta por la "verdad" del marxismo: ¿Era posible la transformación de la "sociedad" toda, o por el contrario ese había sido el error capital del discurso marxista?

No obstante este debate, el resultado general fue que en las obras de muchos teóricos/militantes del marxismo la conocida tesis dualista Burguesía/Proletariado a secas,

\footnotetext{
${ }^{25}$ Nahuel Moreno, Las revoluciones del siglo XX (Buenos Aires: Antídoto, 1984a) 58.

${ }^{26}$ John Beverley, "Sobre la situación actual de los estudios culturales, en Asedios a la Heterogeneidad Cultural”, Homenaje a Antonio Cornejo Polar, ed. J.A. Mazzotti y J. Cevallos (Perú:Asociación Internacional de Peruanistas, 1996) 9.
} 
comenzaba a ser desbordada ampliamente. En los análisis concretos se presentaba la necesidad de complejizar la pretendida polarización social. En este sentido, no es casual, entonces, que en esta época comiencen a re-aparecer y a re-formularse categorías tales como: "mito", "bloque histórico", "masa”, "desarrollo desigual y combinado", "subalternidad”, "poscolonialismo", "hegemonía”, entre otros.

De este modo, teorizaciones como la de Spivak, vienen a mostrar que el vínculo trabajado por el marxismo entre capitalismo global, en tanto modo de producción que supone un proceso de explotación económica, y la configuración de los Estados-Nación, como dominación geo-política, adquiere un análisis tan macrológico que hace que sea imposible que de éste se desprenda un análisis de "la textura micrológica del poder" ${ }^{27}$ (Spivak, 2003:314). Complementario con estos supuestos, Spivak sostiene que el sujeto no puede ser pensado de forma unívoca, dado que supondría una reducción en un doble sentido. Por un lado, se presentaría la imposibilidad de pensar los vínculos coloniales y poscoloniales, y al sujeto que éstos configuran (colonizado subalterno). Y por otro lado, aunque existiera la posibilidad de pensar este tipo de subjetividades en las coordenadas clásicas, se coartaría la potencialidad de pensar a ese sujeto ya no de modo cerrado y uniforme, sino como portador de una heterogeneidad irresoluble.

La idea de un desarrollo desigual de los procesos sociales se hace fuerte en esta época. Así se enfatiza en los análisis la idea de un carácter asimétrico de la economía en las distintas regiones y de los desarrollos sociales de un área a otra: "las mismas clases o elementos que eran dominantes en un área (...) podían estar entre los dominados en otra. Esto (...) creaba ambigüedades y contradicciones en actitudes y alianzas" ${ }^{28}$, entre el campesino, el proletariado, los desocupados, etc., no obstante, todos pudiesen ser comprendimos como clases subalternas.

De este modo, la mayor crítica que pesó sobre el discurso marxista, en este contexto, se basó en cómo pensar la subjetividad una vez que el sujeto de la Historia se ha desdibujado, o en algunos casos se ha declarado inexistente. Stuart Hall sostiene que es preciso realizar una reconceptualizacion del sujeto sin abandonarlo como categoría, puesto que si bien no puede ser pensado a la vieja usanza, si él no podrían pensarse cuestiones claves de la coyuntura actual. Por lo tanto, la propuesta stuarthalliana se afirma en pensar al sujeto de modo descentrado o desplazado, no obstante, dentro de ciertos parámetros del viejo paradigma: "las identidades son puntos de adhesión temporaria a las posiciones subjetivas que nos construyen las prácticas discursivas. Son el resultado de una articulación o «encadenamiento» exitoso del sujeto en el flujo del discurso" ${ }^{29}$.

Las teorizaciones de Ernesto Laclau se despliegan en un camino similar al presentado por Hall. Laclau, propondrá que, junto con la noción de sujeto, es necesario re-trabajar la categoría de "estructura" sostenida por el discurso marxista. La estructura, de este modo, lejos de ser aquella que conforma las determinaciones económicas, será una estructura discursiva; y por tanto todo sujeto será entendido como "posición de sujeto”. Más es

27 Gayatri Spivak, “¿Puede hablar el subalterno?”, revista colombiana de antropología, volumen 39, (2003):314.

${ }^{28}$ Gayatri Spivak, “¿Puede hablar ...” 323.

${ }^{29}$ Stuart Hall, “Introducción: ¿quién necesita «identidad»?”, Cuestiones de identidad cultural, ed. Stuart Hall y Paul Du Gay (Buenos Aires: Amorrortu, 1996) 20. 
importante comprender que al hablar de posiciones de sujeto, Laclau no está pensado en la determinación última de una posición, sino en la "sobredeterminación” de posiciones que constituyen al sujeto, retomando el concepto althusseriano de sobredeterminación ${ }^{30}$.

\section{Moreno y Beverley, como pensadores del marxismo ante su crisis}

Como marcábamos más arriba, si bien ambos autores partes de un diagnostico de "derrota” y de "traición” de los procesos revolucionarios del siglo XX, las diferencias que presentan en estos análisis los conduce, de alguna manera, a teorizar de modos diferentes la "crisis del marxismo".

El primer gesto teórico-político de Moreno será el de reformular la premisa clásica del devenir histórico inevitable hacia el socialismo, afirmando que:

El tiempo nos ha demostrado que no existe una ley científica por la cual se llega inexorablemente a la catástrofe final del capitalismo y el comienzo del socialismo. El problema es mucho más complejo, ya que entran en juego los sujetos históricos, que son las clases, con sus sectores, grupos y dirigentes. La crisis definitiva de una sociedad está íntimamente relacionada con las luchas y los acuerdos para la lucha entre todos ${ }^{31}$.

En este sentido, Moreno resuelve la tensión existente en el marxismo entre "lucha de clases" o "sucesión de modos de producción” como motor de la historia, a favor de la "lucha”. Esta decisión, lo conduce a afirmar que si la lucha es el motor de la historia ya no es posible prever antemano su resultado. En otras palabras, el desarrollo de las fuerzas productivas puede haberse detenido, mas ya no podemos concebir que dicho estancamiento implique el cambio de un modo de producción por otro, ya que el resultado estará signado por la "lucha”: "El motor absoluto y total del proceso histórico es la lucha, luchas entre tribus, luchas entre naciones, luchas entre razas, luchas entre grupos humanos, luchas entre sectores burocráticos, luchas entre grupos de las tribus.(...) Es decir, la lucha es una constante del proceso histórico" ${ }^{32}$. No obstante, lo que aparece como innegable, es la existencia de la lucha -de clases-. La "crisis del marxismo" es definida, por lo tanto, dentro de un problema teórico, ya que es inevitable a partir de este "descubrimiento" reformular constantemente los saberes del marxismo. Éste es considerado por Moreno como una “ciencia abierta”, permeable a incorporar nuevos saberes y campos de pensamiento. La lógica marxista es, de esta manera "la única lógica concreta, científica existente, eficiente y con pretensiones de tal, que ha logrado un progreso importante, aunque la mayor parte de las veces inconsciente, práctico, en manos de científicos que pueden o no declararse marxistas” ${ }^{33}$. En un segundo término, no por ello menos importante, la crisis del marxismo

\footnotetext{
${ }^{30}$ Ernesto Laclau y Chantal Mouffe, Hegemonía y estrategia socialista. Hacia una radicalización de la democracia (Buenos Aires: Fondo de cultura económica, 2004).

${ }^{31}$ Nahuel Moreno, Conversaciones...2.

32 Nahuel Moreno, “Sobre los sujetos históricos. Charla-debate con André Gunder Frank”, Biblioteca digital www.nahuelmoreno.org, (1984b), consultado al 25/02/2015.

${ }^{33}$ Nahuel Moreno, Nahuel Moreno, Conversaciones....101.
} 
es para Moreno una crisis política, una crisis de dirección internacional, la cual debería luchar por el advenimiento del socialismo. De alguna manera, el balance que realiza Moreno en relación a las revoluciones cubana y nicaragüense, como vimos más arriba, referencia el por qué el rol de la “dirección” adquiere un cariz fundamental. Es decir, si el problema de estas revoluciones se manifestaba en su "contenido clasista”, era porque tanto la dirección del FSLN y del castrismo, habían pactado con sectores burgueses. De este modo, Moreno sentenciará al respecto, "no existe una gran dirección internacional, con influencia de masas que se plantee la perspectiva de derrotar al imperialismo" ${ }^{34}$. Moreno consideraba que cabría la posibilidad de que al caer el stalinismo como práctica política, que era un fuerte obstáculo para la resolución de la crisis del marxismo, podría surgir una nueva dirección a nivel mundial.

La relación entre saber y verdad se articularía en Moreno, dando como giro resolutivo la necesidad de que en gran parte el saber del marxismo tenga que reformularse, mas no así su verdad, ya que ésta solo puede sostenerse o no a través de la lucha. Como desarrolla Palti, el marxismo "a fin de preservarse como práctica revolucionaria, de conservar su esencia (su Verdad implícita), debería reformularse constantemente, reconstruir una y otra vez todo su saber” 35 .

Para comenzar a trazar las líneas en torno a la crisis del marxismo que rastreamos a lo largo de ciertos escritos de Beverley, tendríamos que comenzar diciendo que su postura parte de un balance de "derrota”, a la vez que de una ruptura. En este sentido, el grupo de estudios subalternos latinoamericano se forma luego de la derrota en las elecciones presidenciales nicaragüenses de 1990, lo cual supone para esta generación de intelectuales que el sueño de la revolución había fracasado. Proceso que lejos de coartarles la posibilidad de reflexionar sobre los problemas emancipatorios, los conduce a apostar por "un nuevo programa, ajustado a las condiciones actuales, que incluyen el colapso de la alternativa representada por el bloque soviético y la crisis del marxismo" ${ }^{36}$. Es sobre este punto donde se presenta la ruptura. A grandes rasgos podríamos decir que ciertos integrantes del grupo pertenecían a la corriente de estudios culturales de García Canclini y a partir de este contexto internacional, sobre todo con la derrota electoral del FSLN, comienzan a pensar que los estudios sobre subalternidad no deben ser pensados como una disciplina menor: "en vez de pensar que los estudios subalternos son un componente dentro de los estudios culturales, sería más correcto decir que representan una manera alternativa de articular las preocupaciones de los estudios culturales" ${ }^{37}$. Inspirados por el grupo de estudios subalternos sudasiaticos y por ciertos ejes de debate del Centro de estudios culturales de Birmingham, los estudios subalternos latinoamericanos criticaban "los estados de izquierda y las organizaciones partidistas por su liberalismo (...) [y] les incomodaba el 'multiculturalismo triunfante' que hablaba poco de la descentralización de la riqueza y la democratización del poder político" ${ }^{38}$.En este sentido, como afirmaba Beverly, el grupo de estudios subalternos se erigía como un método defensivo, al mismo tiempo que contra ofensivo: "Representan para

\footnotetext{
${ }^{34}$ Nahuel Moreno, Nahuel Moreno, Conversaciones....14.

${ }^{35}$ Elias Palti, Verdades... 89.

36 John Beverley, “Sobre la situación...” 13-14.

37 John Beverley, “Sobre la situación...” 10.

38 Mónica Szurmuk y Robert McKee Irwin, Diccionario... 255.
} 
nosotros una especie de correctivo, por un lado, a la crisis de la izquierda; por otro, a lo que vemos como la despolitización de los estudios culturales a consecuencia de su institucionalización" 39 .

Si como sostiene Beverley, luego de la "derrota” del discurso marxista, el proyecto de los estudios culturales de García Canclini suponía que el "capitalismo es (...) simplemente la nueva condición de vida -algo inevitable-” ${ }^{40}$, para el grupo de estudios subalternos la crisis de marxismo deja abierta la posibilidad de pensar la premisa emancipatoria, junto con el desafío teórico de crear nuevas categorías de análisis. De este modo, las palabras claves que presenta el grupo para re-teorizar la problemática de lucha son: “cultura”, “democratización”, “globalización” y algunos “post” (postmarxismo, postmodernismo, postestructuralismo). Junto con estos conceptos, se abría el debate acerca de abandonar categorías tales como "modernización”, “dictadura del proletariado”, "partido”, “revolución”, “centro-periferia”, “desarrollo”, “nacionalismo” y “liberación nacional”, para remplazarlos por nociones que den cuenta de las nuevas especificidades de los social, a la vez que continuasen manteniendo intacta la apuesta rupturista de lucha. De este modo, “pluralismo”, “democracia”, “consenso”, “subalternidad”, “desplazamientos de poder”, entre otros, parecían conceptualizaciones más pertinentes para los objetivos del grupo ${ }^{41}$.

La crisis del marxismo se presentaba, entonces, como una gran crisis teórica y de método, ya que el discurso marxista había quedado, en cierto sentido, desactualizado frente a las grandes transformaciones a nivel mundial, no pudiendo ver las complejidades y las especificidades de los distintos países y procesos sociales. Este desajuste, al mismo tiempo, había generado que el "marxismo" cometiese atroces crímenes contra aquellos sectores por los cuales supuestamente había luchado en el pasado, a la vez que, paradójicamente, operaban con las mismas reglas que los dominadores.

Ahora bien, si perderse dentro de esa paradoja representaba la crisis del comunismo del siglo XX, la nueva tarea era explicitar la paradoja para sortear sus obstáculos. De este modo, se hacía necesario, para Beverley, trazar los límites que la paradoja había adquirido. Si la paradoja del siglo XX había estado signada por el rol preponderante de los Estadosnación, de ahí la apuesta marxista por la "toma del poder del Estado"; la paradoja contemporánea se regía por los procesos de desjerarquización operantes dentro de la lógica neoliberal. En este sentido, ya no era necesario pensar la lucha como un problema de "toma del Estado" sino como una lucha en torno a la hegemonía de los subalternos que reconquistase "el espacio de desjerarquización cedido al mercado y al neoliberalismo" ${ }^{2}$. El problema radicaba en que, precisamente en esa "articulación ideológica”, se abría el peligro de no comprender la desjerarquizacion desde una "apertura hacia la diferencia y nuevas formas de libertad y auto-desarrollo" 43 .

El balance que sostiene Beverley en relación a la crisis del marxismo se afirmaba en la posibilidad de sostener la verdad marxista en tanto premisa de lucha emancipatoria (por

\footnotetext{
39 John Beverley, “Sobre la situación...” 10.

40 John Beverley, "Sobre la situación...” 13.

${ }^{41}$ John Beverley, José Oviedo y Michael Aronna, "Manifiesto inaugural”, The Posmodernism Debate in Latin America (Duke University Press: Grupo latinoamericano de estudios subalternos, 1995).

42 John Beverley , “La persistencia del subalterno”, en el panel Canto del cisne de los estudios culturales, organizado por Abril Trigo (Washington DC: LASA, 2001): 55.

43 John Beverley , “La persistencia...”55.
} 
otros medios: lucha por la hegemonía de los subalternos en el plano de la desjerarquización abierto por la lógica neoliberal), a costa de trastocar sus métodos y su saber.

En resumen, tenemos dos maneras diferentes de entender la crisis del marxismo. Mientras que Moreno nos sugiere que el marxismo debe permanecer en una constante reformulación de su saber sin abandonar su contradicción fundamental (burguesía/proletariado), más no por ello debe dejar de creer y de luchar por su verdad; Beverley y el grupo de estudios subalterno nos propondrán permanecer, de algún modo, dentro del discurso marxista, reformulando sus saberes, y seguir luchando por la verdad a pesar (e incluso a causa) de que "la verdad" se haya transformado. A partir de lo relevado, veremos que estos autores propondrán una revisión de las categorías clásicas del marxismo develando distintas maneras de concebir al sujeto, y su vinculación con la lucha, la estructura, y las formas de organización político-culturales. En efecto, ¿Cómo impactan estas conceptualizaciones de la crisis del marxismo a la hora de pensar las subjetividades contemporáneas? El "descubrimiento" del descentramiento de la historia, una realidad social cada vez más opaca, el cuestionamiento del carácter determinante de la economía, desbordarán el concepto clásico de clase social y marcarán las limitaciones explicativas de la aplicación de esta categoría.

Moreno, como vimos, afirmará que son los hombres en lucha y las dinámicas que adquieren estas luchas las que demarcan el sentido de la historia. Ahora bien, esta lucha -como motor de la historia- se articula y es explicada, para el morenismo, como una tensión permanente entre los conceptos marxistas de estructura y la superestructura. O para ser más precisos, con la distinción entre el sujeto social y el sujeto político. Moreno formulará la hipótesis de que ya no es posible pensar un Sujeto histórico, sino dos: “¿Cuáles son los sujetos? Uno es qué sector de explotados va a dirigir la revolución, quién la va a hacer, (...), es decir, el sujeto social. Y el segundo sujeto es el de los partidos”44, el sujeto político.

En este sentido, es impórtate explicitar que entiende Moreno, por "sujeto social". En términos generales, si bien retoma el término marxista de "estructura", la comprende de una manera más compleja que la teorizada por Marx. Moreno recoge el término masas, utilizado por Trotski, para hacer referencia a todo sujeto explotado, a todo aquel que vive de su fuerza de trabajo. Al mismo tiempo, el término "masas" fue utilizado políticamente para convocar a las distintas "clases" a la lucha. En un continente como el latinoamericano, se hacía prácticamente imposible reivindicar la lucha "obrera”, sin tener en cuenta al campesinado (pensamos en países como Perú, Bolivia, entre otros) y a la clase media urbana (sector muy importante en la política Argentina, por ejemplo). De esta manera, y al ser un tema poco desarrollado por Marx, se hacía necesario para el morenismo precisar el concepto de "clase". La masa vendría ahora a explicar aquello que excedía a la clase obrera como tal.

Ahora bien, para Moreno el sujeto masa no se caracteriza, en su definición, como el sujeto que lucha. La masa comienza a luchar como resultado de la extrema explotación del sistema capitalista, explotación la cual conforma el carácter subjetivo de la masa. La propia crisis del sistema capitalista es la que crea la necesidad de luchar; a la vez que el grado de desarrollo del movimiento de masas es el que determina que la movilización estalle o no.

\footnotetext{
${ }^{44}$ Nahuel Moreno, “Sobre los sujetos...”.
} 
En otras palabras, la conciencia de las masas está determinada por "la necesidades que sufren y de las condiciones en que se encuentran para enfrentar a los explotadores" 45 . Para Moreno, la conciencia del sujeto social es independiente del sujeto político. Es decir, si la “conciencia” del sujeto masas se da en las mismas luchas que ella genera, el rol el sujeto político es el de disputar la hegemonía de las masas, a través de la lucha con otras organizaciones y tendencias: "El partido revolucionario tiene que ganar la hegemonía política del movimiento de masas. Esto se consigue trabajando sobre ellos, con una política que se plantea para que ellos la tomen” ${ }^{46}$.

De este modo, creemos que el pensamiento de Moreno radica en el intento de concebir a "la acción subjetiva de un modo que ésta no aparezca como un mero complemento de las determinaciones materiales, pero que tampoco las niegue”. ${ }^{47}$. Se distingue, entonces, una “inversión de la ley de causalidad histórica”, porque "ya no son los factores objetivos sino el más subjetivo de ellos, la presencia o no de un partido revolucionario (el sujeto político), el que se convierte, (...), en el determinante en última instancia” ${ }^{48}$. La tensión entre la dislocación de la lógica estructural y su mantenimiento se convertirá en una constante en la obra de Moreno: "La irrupción de la temporalidad, la introducción de un elemento de contingencia en el seno del pensamiento marxista, no conlleva la resolución de la contradicción entre los dos principios motores de la historia. (...) El trotskismo afirma simultáneamente la necesidad y la imposibilidad de pensar un orden poscapitalista que no sea socialista" ${ }^{49}$. En consecuencia, la apuesta morenista que se ancla en marcar una fisura que habilita el campo de la lucha política: disputa hegemónica, sujeto político, aun presupone un espacio estructural que constituye la identidad, sin fallas, de un sujeto social (las masas).

Por su parte, Beverley y el grupo de estudios subalternos propondrán al igual que Moreno que ya no es posible pensar un Sujeto histórico, como lo formulaba el marxismo clásico. No obstante, nuevamente, la resolución a tal planteo encontrará otros caminos a los planteados por el argentino. El punto nodal radica, en la imposibilidad que plantea este grupo de continuar pensando la estructura, y las relaciones que ésta generaba como lo hacia el marxismo clásico, en dos sentidos. Primero, el sujeto (de la lucha) ya no puede ser pensado como Uno. Es decir, este sujeto no puede ser pensado en términos reduccionistas, debe comprenderse por el contrario como algo múltiple, no determinado, de ahí la elección del término subalterno:

El subalterno no es una sola cosa. Se trata, insistimos, de un sujeto mutante y migrante. Aun si concordamos básicamente con el concepto general del subalterno como masa de la población trabajadora y de los estratos intermedios, no podemos excluir a los sujetos 'improductivos', a riesgo de

\footnotetext{
${ }^{45}$ Nahuel Moreno, El partido y la revolución. Teoría, programa y política. Polémica con Ernest Mandel (Buenos Aires: Antídoto, 1989) 340.

${ }^{46}$ Nahuel Moreno, El partido...28.

${ }^{47}$ Elias Palti, Verdades...69.

${ }^{48}$ Elias Palti, Verdades...58.

${ }^{49}$ Elias Palti, Verdades...81.
} 
repetir el error del marxismo clásico respecto al modo en que se constituye la subjetividad social ${ }^{50}$.

En segundo lugar, la subalternidad no emerge de la estructura, como el sujeto marxista clásico, sino que por el contrario disloca las cristalizaciones estructurales. Así la emergencia política del subalterno se encuentra en "las fisuras que dejan las formas hegemónicas y jerárquicas" ${ }^{51}$, de este modo el locus en donde la subalternidad habla como sujeto político y social, requiere una exploración de los márgenes del estado. Para los estudios subalternos ya no es posible pensar la escisión entre sujeto social y sujeto político, dado que la propia posibilidad del surgimiento de la subalternidad, como sujeto de cambio, está dada por la articulación entre lo social, lo político y lo cultural que generan las fallas estructurales.

\section{Conclusiones}

Los desplazamientos conceptuales que realizan Moreno y Beverley, en relación al discurso marxista clásico, encuentran su condición de posibilidad en el acto mismo de pensar la "crisis del marxismo". No obstante, ambas apuestas teórico-políticas presentan dos maneras diferentes de entender esta crisis. Mientras que Moreno nos sugiere que el marxismo debe permanecer en una constante reformulación de su saber sin abandonar su contradicción fundamental (burguesía/proletariado), más no por ello debe dejar de creer y de luchar por su verdad; Beverley y el grupo de estudios subalterno nos propondrán permanecer, de algún modo, dentro del discurso marxista, reformulando sus saberes, y seguir luchando por la verdad a pesar (e incluso a causa) de que "la verdad" se haya transformado. A partir de lo relevado, veremos que estos autores propondrán una revisión de las categorías clásicas del marxismo develando distintas maneras de concebir al sujeto (masa en el caso de moreno, subalterno en el caso de Beverley), y su vinculación con la lucha, la estructura, y las formas de organización político-culturales.

La obra de ambos autores, si bien presentan distintas particularidades teóricas como vimos a lo largo del artículo, nos muestran los riesgos y las ventajas de asumir la des-realización de aquella Historia que el marxismo pregonaba. Por tal motivo, estas formas de concebir la importancia de las formaciones político-culturales, y las subjetividades que aquellas permiten colegar, abren posibilidades para un pensamiento político-cultural crítico de recrear sus conceptos, desde una perspectiva latinoamericana de la crisis del marxismo.

\section{Obras Citadas}

\footnotetext{
${ }^{50}$ John Beverley, José Oviedo y Michael Aronna, "Manifiesto...”11.

${ }^{51}$ John Beverley, José Oviedo y Michael Aronna, "Manifiesto...."2.
} 
Acha, Omar, "La irresistible seducción filosófica del marxismo". Revista Herramienta No33, Argentina, 2006.

Anderson, Perry, “¿Existe una crisis del marxismo?”. Revista Dialéctica ํ⒐ México, 1980. 145-158.

Antunes, ricardo, ¿Adiós al trabajo? ensayo sobre las metamorfosis y el rol central del mundo del trabajo. Buenos Aires: Ediciones Herramienta, 2003.

Althusser, Louis, Marx dentro de sus límites, Madrid: Akal, 2003.

Althusser, Louis, "Dos o tres palabras (brutales) sobre Marx y Lenin”. Eco. Revista de la cultura de Occidente No 197, Bogotá, 1978.

Beverley, John, Oviedo, José y Aronna, Michael, "Manifiesto Inaugural", The posmodernism debate in latin america, Duke university press: Grupo latinoamericano de estudios subalternos, 1995.

Beverley, John, "Sobre la situación actual de los estudios culturales, en asedios a la heterogeneidad cultural”, Libro de homenaje a Antonio Cornejo Polar, ed. J.A. Mazzotti y J. Cevallos, Perú: Asociación internacional de peruanistas, 1996.

Beverley, John, "La persistencia del subalterno". Panel Canto del cisne de los estudios culturales, organizado por Abril Trigo, LASA, Washington DC, 2001.

Buenfil Burgos, Rosa Nidia, "Foucault y la analítica del discurso". Ponencia para coloquio aniversario del nacimiento de Michel Foucault, México, 1996.

Castoriadis, Cornelius, La institución imaginaria de la sociedad. Marxismo y teoría revolucionaria. Barcelona: Tusquets, 1993.

Derrida, Jacques, Espectros de Marx. El estado de la deuda, el trabajo del duelo y la nueva internacional. Madrid: Trotta, 1995.

Hall, Stuart, “Introducción: ¿quién necesita «identidad»?”, Cuestiones de identidad cultural, comp. H. Stuart y P. Du Gay. Buenos Aires: Amorrortu editores, 1996.

Martí, Salvador, Nicaragua postrevolucionaria: el laberinto sandinista y la difícil consolidación democrática. Afers internacionals, № 34-35, 1996.

Moreno, Nahuel, Conversaciones con Nahuel Moreno. Buenos Aires: Antídoto, 1986.

Moreno, Nahuel, El partido y la revolución. Teoría, programa y política. Polémica con Ernest Mandel. Buenos Aires: Antídoto, 1989.

Moreno, Nahuel, Las revoluciones del siglo XX. Buenos Aires: Antídoto, 1984 (a).

Moreno, Nahuel, "Sobre los sujetos históricos. Charla-debate con André Gunder Frank", Biblioteca digital www.nahuelmoreno.org, consultado al 25/02/2015, 1984(b).

Laclau, Ernesto y Mouffe, Chantal, Hegemonía y estrategia socialista. Hacia una radicalización de la democracia. Buenos Aires: Fondo de cultura económica, 2004.

Löwy, Michael, “Marx un siglo después”. El rodaballo, Revista de cultura y política № 1 , 1994.

Palti, Elías José, Verdades y saberes del marxismo. Reacciones de una tradición política ante su "crisis". Buenos Aires: Fondo de cultura económica, 2005.

Spivak, Gayatri, “¿Puede hablar el subalterno?”, Revista colombiana de antropología, volumen 39, 2003.

Szurmuk, Mónica y Mckee Irwin, Robert, Diccionario de estudios culturales latinoamericanos. México: Siglo XXI editores, 2009.

Trotsky, León, La revolución permanente. Buenos Aires: el Yunque editora, 1973. 
Torfing, Jacob, Una revisión al análisis de discurso, en debates políticos contemporáneos. En los márgenes de la modernidad. México D.F.: Plaza y Valdés, 1998.

Vilas, Carlos, "Nicaragua: el camino de la derrota electoral y el porvenir de la revolución sandinista”, Revista realidad n 14, Marzo-Abril, 1990.

RECIBIDO: 3 abril 2015

ACEPTADO: 26 mayo 2015 